\title{
Author Correction: Election polling errors across time and space
}

Will Jennings (1) and Christopher Wlezien (1)

Correction to: Nature Human Behaviour https://doi.org/10.1038/s41562-018-0315-6, published online 12 March 2018.

In the version of this Letter originally published, a coding error resulted in the erroneous weighting of the measure of the average annual absolute error on the margin by the number of parties standing in an election rather than as a single value for each election. This led to an incorrect depiction of the data in Fig. 2c,e. This coding error has now been corrected. The graphic and quantitative changes in the corrected Fig. 2c,e are contrasted with the originally published display items below. The conclusions of the paper are not affected and no changes were made to the text. The error has been corrected in the HTML and PDF versions of the article. 


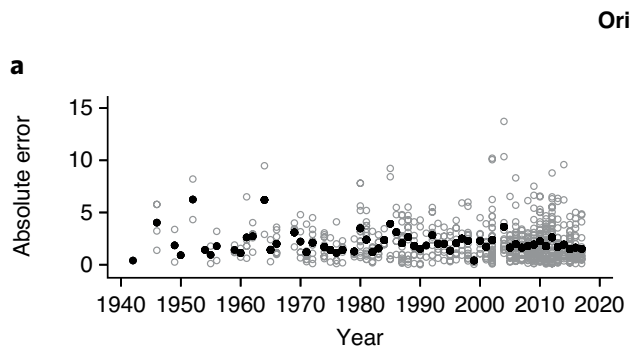

Original
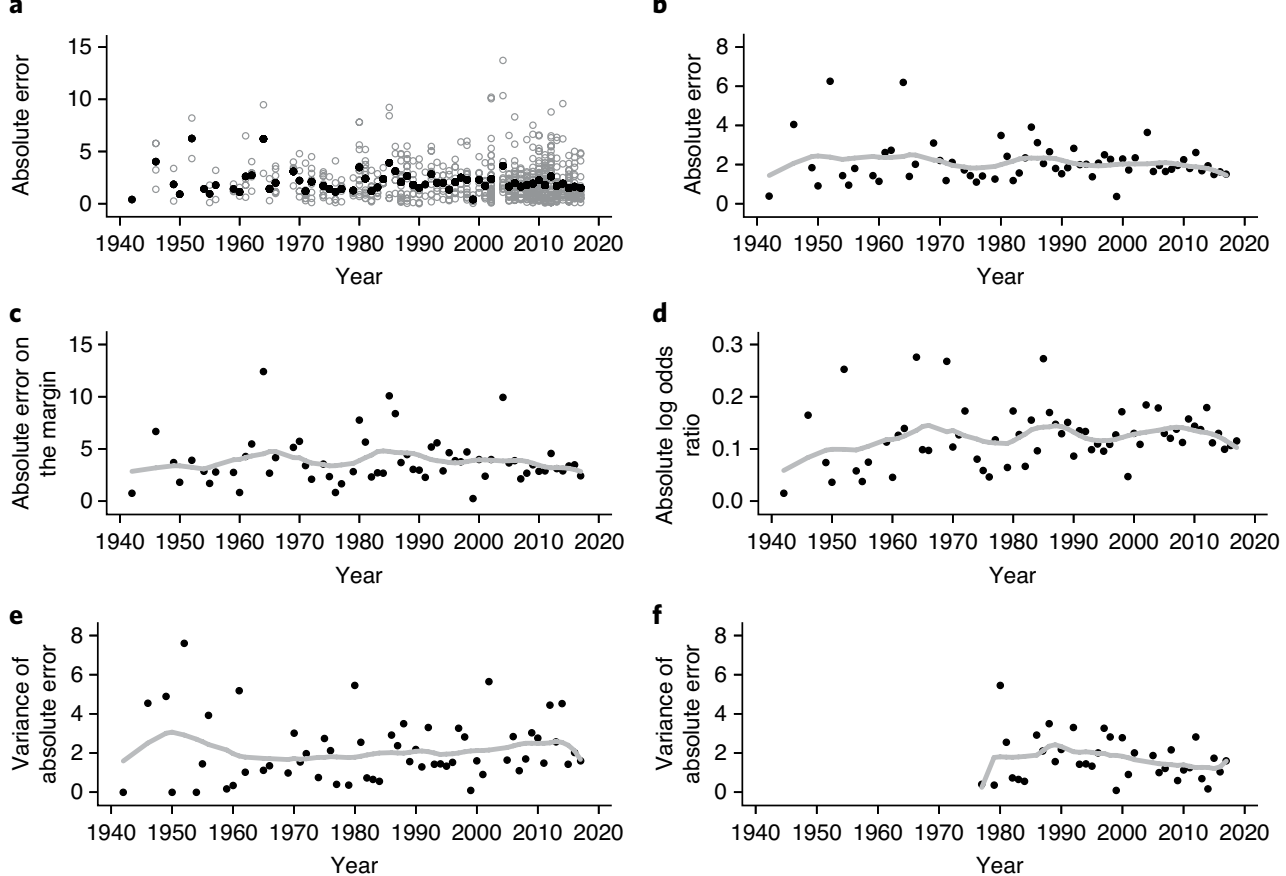

Corrected

a
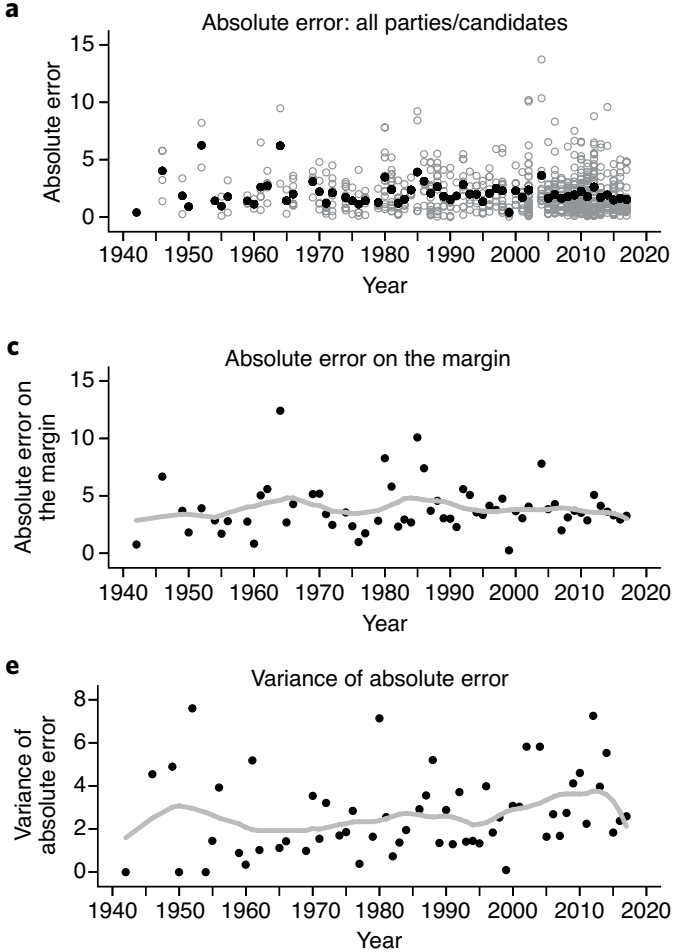

b
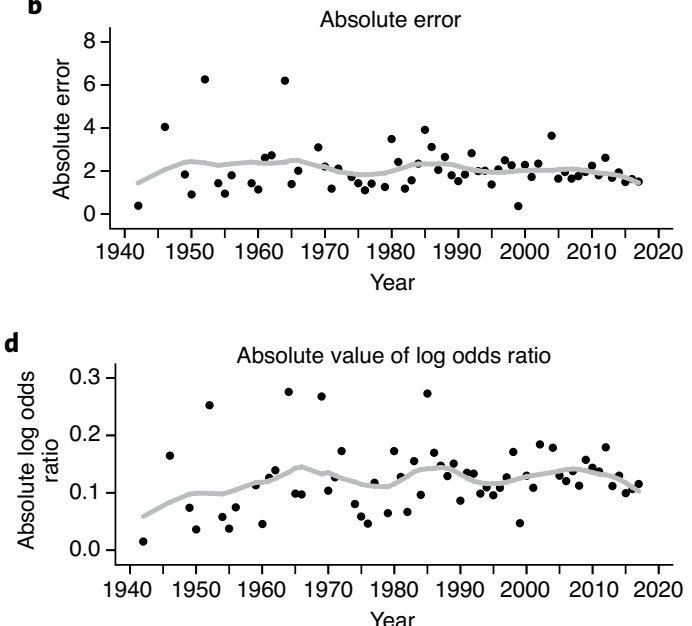

$\mathbf{f}$

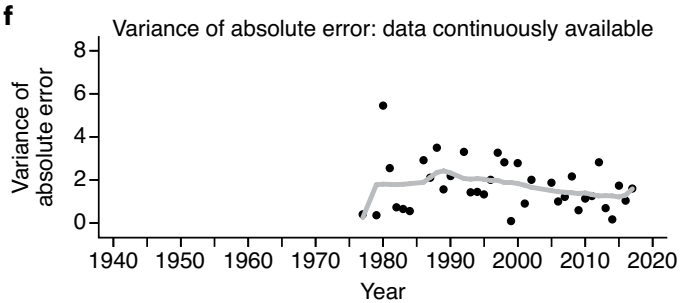

Fig. 2 | Orginal and corrected.

Published online: 26 June 2020

https://doi.org/10.1038/s41562-020-0914-x

(C) The Author(s), under exclusive licence to Springer Nature Limited 2020 